\title{
A Digital Loudspeaker: Experimental Construction
}

\author{
P. Valoušek
}

To verify the principal functionality of a digital loudspeaker the experimental construction of a digital loudspeaker was designed. This system consists of signal processing unit and transducer array. Both parts offer 8-bit precision and wide a spectrum of sampling frequencies. The signal processing unit is based on a programmable logic device which provides a flexible system for preparing a driving signal. The transducer array is formed by conventional dynamic transducers arranged in a circle. The initial measurements and listening tests provide acceptable results that are valuable for further digital loudspeaker developments.

Keywords: Digital loudspeaker, signal processing, transducer array.

\section{Introduction}

\subsection{Principle of a digital loudspeaker}

The fundamental idea of the digital loudspeaker is to shift $\mathrm{D} / \mathrm{A}$ conversion process to the very end of the audio chain. A digital loudspeaker is a single device system which uses direct $\mathrm{D} / \mathrm{A}$ conversion for digital audio signals. This conversion can be performed in various ways and more than one implementation of this system is possible.

The conversion process itself is based on the same principle of summing the partial weighted signals of the input digital signal as in the case of electric converters. Driving signals correspond to single bits of input signal and their binary weights. The acoustic pressures, electromagnetic, electrostatic and other forces can be summed, depending on the construction and the principle of the electro-acoustic conversion of the system. The principle of a digital loudspeaker is shown in Fig. 1.

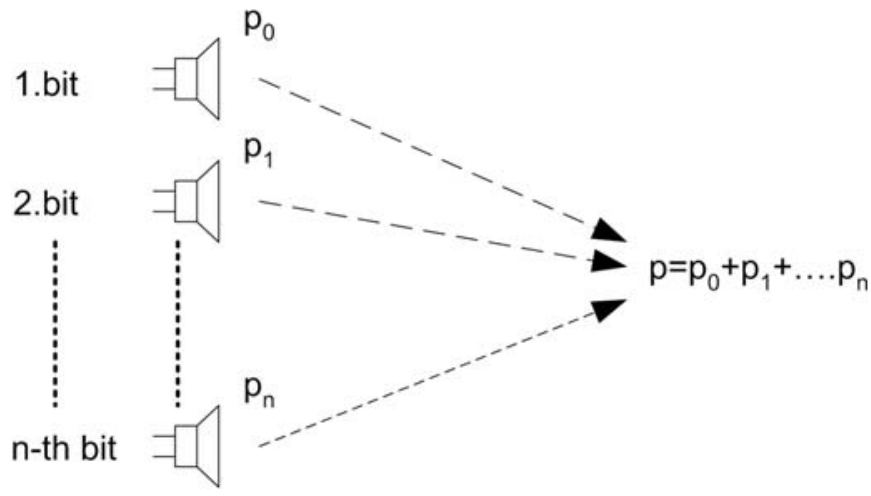

Fig. 1: Principle of a digital loudspeaker with summation of acoustic pressures

\subsection{Driving a digital loudspeaker}

A tri-state driving signal can be prepared by multiplying single data bit streams by the signum bit in the direct digital code of the PCM signal. The resulting bit streams can be directly used to drive the transducers of a digital loudspeaker.

The driving bit streams created from a digital representation of 2 periods of a $1 \mathrm{kHz}$ sine signal at 44.1 sampling frequency are shown in Fig. 2.
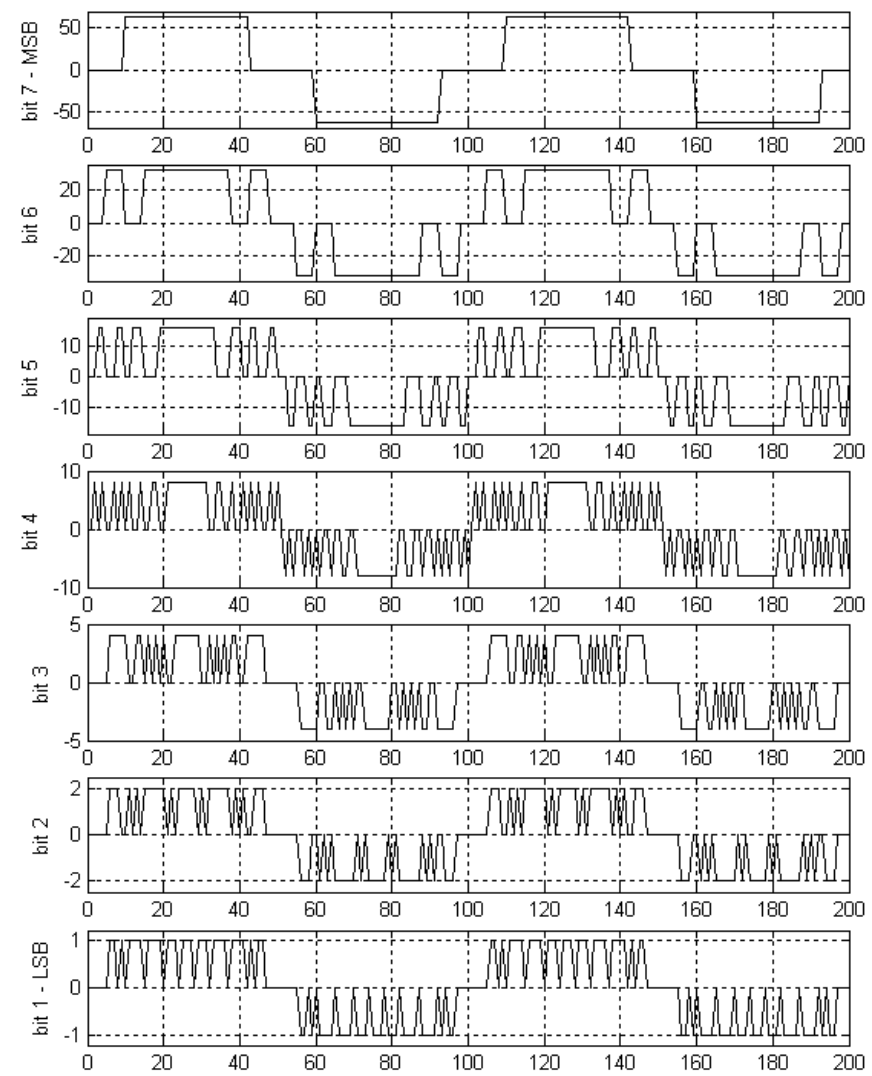

Fig. 2: Driving bit streams

\section{Experimental construction}

\subsection{Signal processing unit}

A serial digital interface SPDIF was chosen as the master input. This digital format is widely used in consumer audio, and all digital audio equipment uses this interface. Therefore the signal source for a digital loudspeaker can be connected to any CD/DVD player or properly equipped personal computer, which can also act as an $\mathrm{A} / \mathrm{D}$ converter and a powerful signal processing unit.

The serial SPDIF signal needs to be decoded into a pure audio data stream and converted to parallel form. Then any signal processing such as binary code conversion, dithering and decimation can be applied.

Parallel data bit streams must be multiplied by the signum bit stream to achieve the tri-state character of the driving sig- 
nal, and must be amplified according to the binary weight of the corresponding bit.

A scheme of experimental signal source chain is shown in Fig. 3.

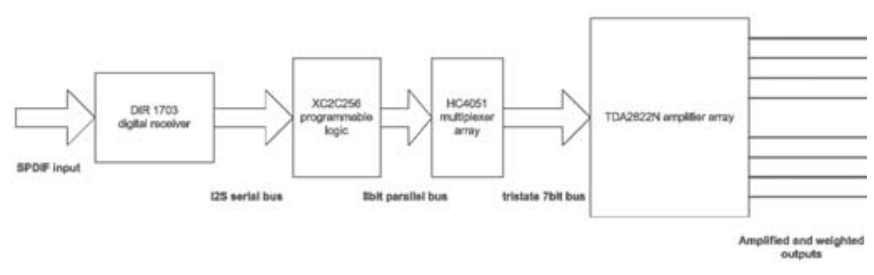

Fig. 3: Signal source chain scheme

The input digital SPDIF signal is decoded by a Texas Instruments DIR1703 digital receiver integrated circuit to an I2S industry standard serial audio bus. The receiver also provides the sample rate detection and master processing clock recovery.

The serial audio bus is received by the Xilinx Cool Runner II programmable logic circuit, which performs the main processing of the serial to parallel conversion, binary code conversion, and optionally decimation. The programmable logic circuit is designed to process two channels with 16 bit data.

The parallel data streams are then tri-state coded by an HC 4051 multiplexer switching matrix with 8 single multiplexer circuits. Currently the switching matrix is able to process 8-bit data in one channel and can easily be upgraded to 16 bits.

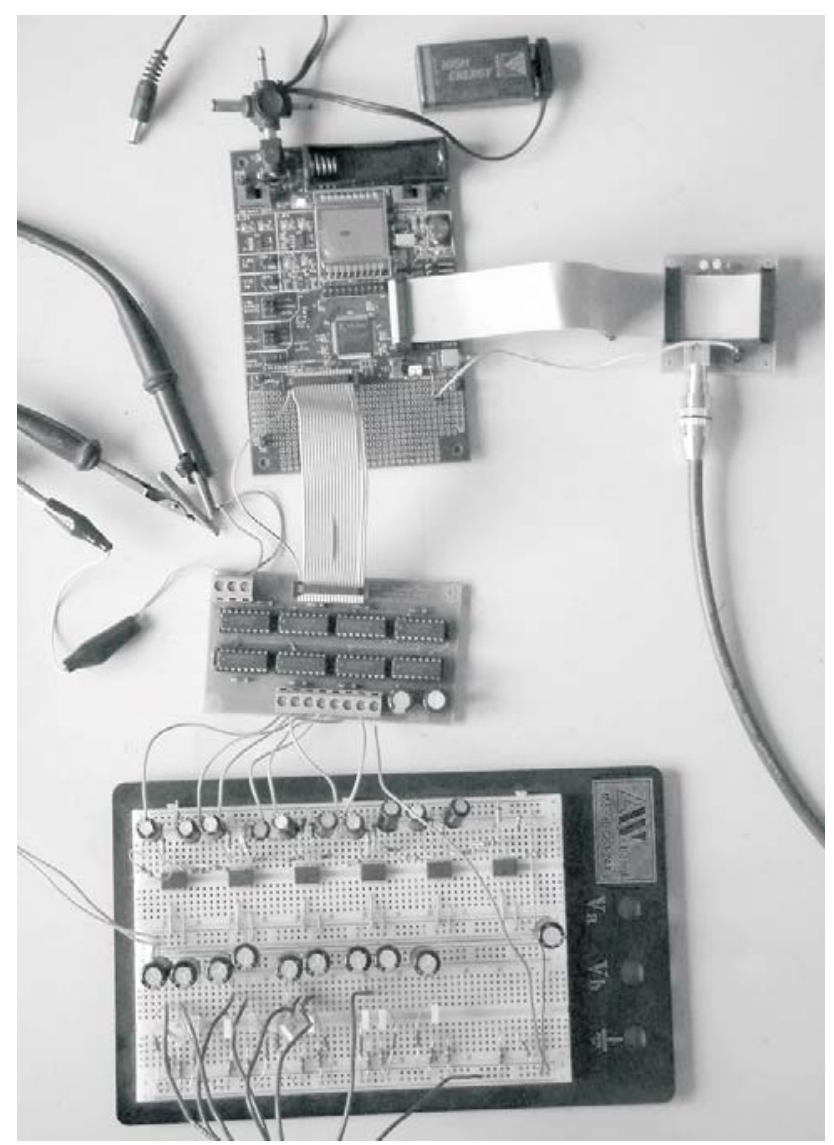

Fig. 4: Signal processing unit chain
In the amplifier section, the data streams can be electrically weighted by resistor dividers on the input side of the TDA2822N power operating amplifier. The amplifier also adjusts the output parameters to conform the transducer characteristics. The operational amplifiers have a very wide frequency characteristic, therefore they can process a digital rectangular signal without distortion. The amplifier is designed for 8 bits and can also easily be upgraded to 16 bits. The experimental signal source chain is shown in Fig. 4 .

\subsection{Transducer array}

For the experimental construction of a digital loudspeaker an array of identical dynamic transducers was created. ARZ 6604 wide-range electro-dynamic transducers were chosen because of their wide frequency response and relatively small dimensions. The impulse and frequency response of an ARZ 6604 transducer is shown in Fig. 5
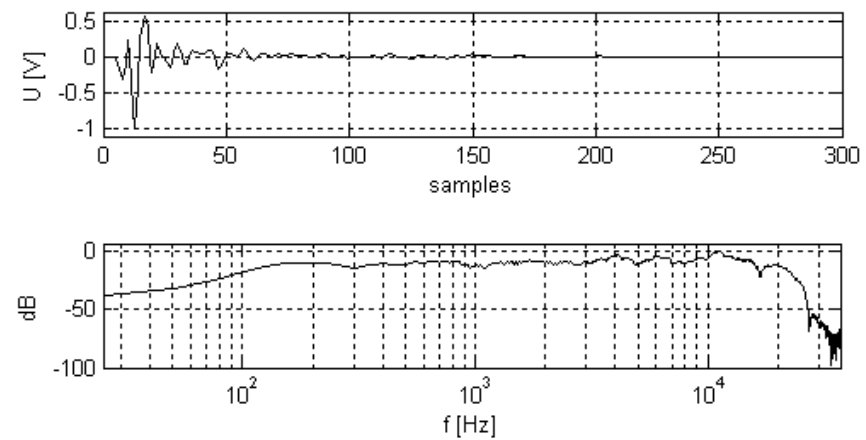

Fig. 5: Impulse and frequency response of an ARZ 6604 wide range dynamic transducer

The array consists of 7 transducers attached to the fiber-glass base plate. The transducers are arranged in a circle. With tri-state coding the 7-transducer array can be driven by an 8-bit digital signal. The experimental array is shown in Fig. 6.

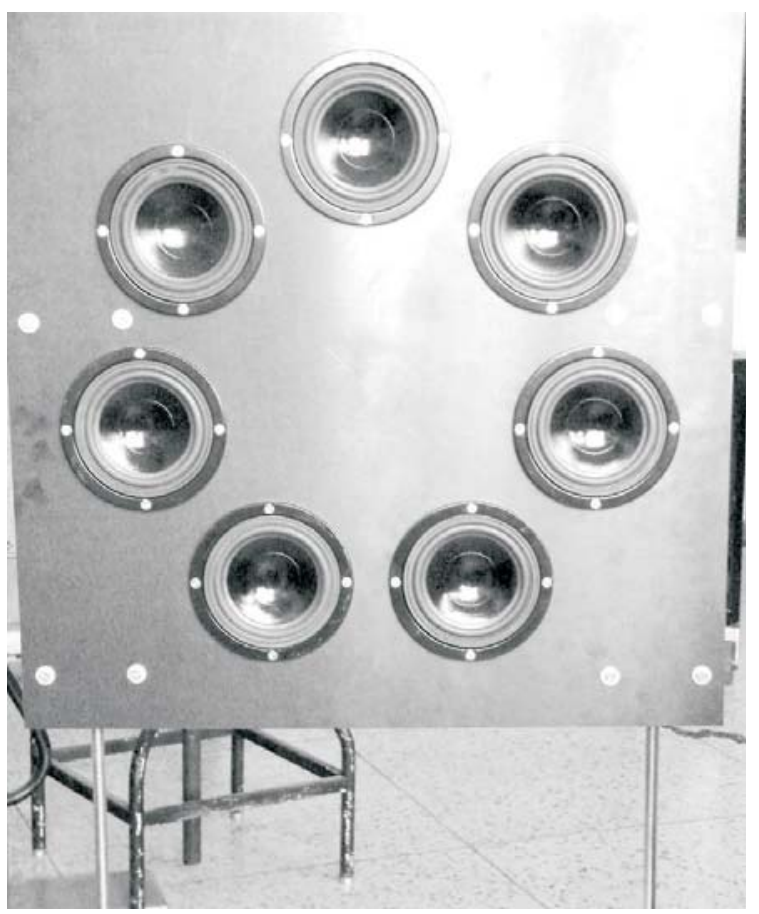

Fig. 6: Transducer array 


\section{Experimental results}

The experimental transducer array was measured at various sampling frequencies from $22 \mathrm{kHz}$ to $96 \mathrm{kHz}$ by harmonic signal, harmonic sweep and music signals with strong dithering applied. Although it suffered from high harmonic distortion, its performance was as expected. Harmonic and other types of distortion are caused by distance delays thanks to large spacing of the transducers in the array. The array was driven by the digital representation of a $1 \mathrm{kHz}$ sine signal at sampling frequency $44.1 \mathrm{kHz}$. The signal produced by a single wide-range transducer at the MSB bit level is shown in Fig. 7 (compare with the MSB bit stream in Fig. 2). The signal produced by the whole array is shown in Fig. 8.

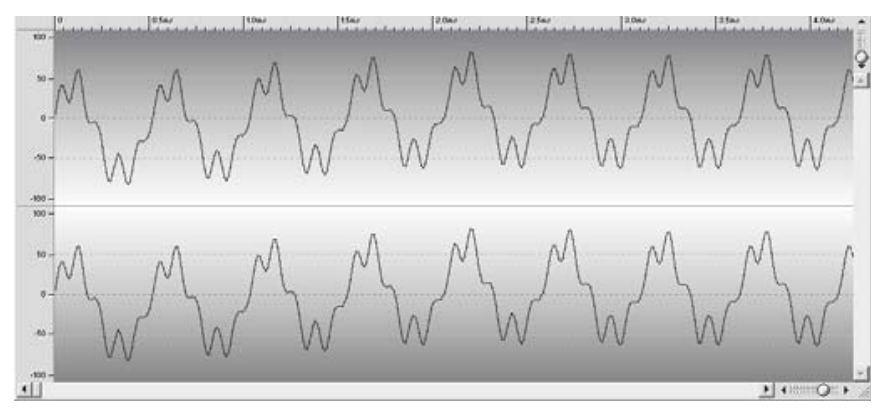

Fig. 7: Signal at MSB level

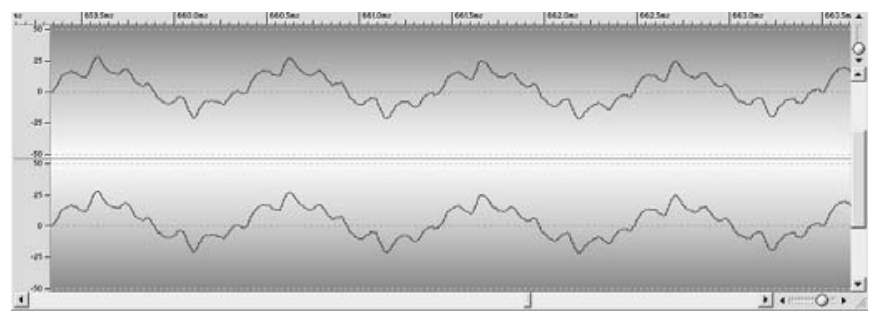

Fig. 8: Signal produced by the whole array

Listening tests were also performed with the receiving point placed in the axis of the transducer array, because this provides identical distances between the individual transducers and the receiving point.

\section{Conclusion}

The principle of the digital loudspeaker has been briefly described and the experimental construction of a driving signal source and an 8-bit transducer array has been introduced. This design is based on conventional dynamic transducers, which have a limited frequency response and quite a long impulse response. Although they are not suitable for digital loudspeaker design, they can be used for experimental purposes to verify the principal functionality of a digital loudspeaker.

\section{Acknowledgments}

This work has been supported by research project MSM 6840770014 "Research in the Area of Prospective Information and Communication Technologies".

\section{References}

[1] Flanagan, J. L.: Direct Digital-to-Analog Conversion of Acoustic Signals. The Bell Systems Technical Journal, Vol. 59 (1980), No. 9.

[2] Busbridge, S. C. et al.: Digital Loudspeaker Technology: Current State and Future Developments, AES 112TH Convention, Munich, Germany 2002 May 10-13.

[3] Huang, Y., Busbridge, S. C., Gill, D. S.: Distortion and Directivity in a Digital Transducer Array Loudspeaker, J. Audio. Eng. Soc., Vol. 49, May 2001, No. 5.

[4] Hayama, A., Furihata, K., Yanagisawa, T.: Electrodynamic Type Plane Loudspeaker Driven by 16 Bits Digital Signal and its Acoustic Responses, Proceedings of ICA Conference, Rome 2001.

[5] Husník, L.: Porovnání různých principů elektroakustické přeměny z hlediska vhodnosti použití v digitálním reproduktoru, Sbornik ATP 2002, Brno, 21.5.2002, p. $38-43$.

[6] Husník, L.: Výhody a nevýhody digitálního reproduktoru. Akustické listy CSAS 4, Vol. 7 (2001), p. 19-20.

[7] Merhaut, J.: Teoretické základy elektroakustiky, Praha, Academia 1985, 328 stran.

[8] Škvor, Zd.: Akustika a elektroakustika, Praha, Academia 2001, 520 stran.

Ing. Pavel Valoušek

e-mail:valousp@feld.cvut.cz

Department of Radioelectronics

Czech Technical University in Prague

Faculty of Electrical Engineering

Technická 2

16627 Praha, Czech Republic 